\title{
Article
}

\section{Towards an understanding of Chinese tourist photography: Evidence from the UK}

Li, Mohan, Sharpley, Richard Anthony john and Gammon, Sean James

Available at http://clok.uclan.ac.uk/19959/

Li, Mohan, Sharpley, Richard Anthony john ORCID: 0000-0002-2135-3206 and Gammon, Sean James ORCID: 0000-0001-5053-8763 (2019) Towards an understanding of Chinese tourist photography: Evidence from the UK. Current Issues in Tourism, 22 (5). pp. 505-521. ISSN 1368-3500

It is advisable to refer to the publisher's version if you intend to cite from the work. http://dx.doi.org/10.1080/13683500.2017.1377690

For more information about UCLan's research in this area go to http://www.uclan.ac.uk/researchgroups/ and search for <name of research Group>.

For information about Research generally at UCLan please go to http://www.uclan.ac.uk/research/

All outputs in CLoK are protected by Intellectual Property Rights law, including Copyright law. Copyright, IPR and Moral Rights for the works on this site are retained by the individual authors and/or other copyright owners. Terms and conditions for use of this material are defined in the policies page.

\section{CLoK}

Central Lancashire online Knowledge www.clok.uclan.ac.uk

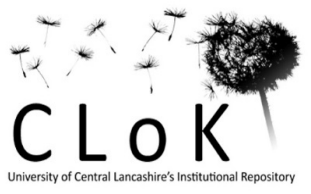




\title{
Chinese Tourist Photography: An Exploratory Study
}

\author{
Mohan $\mathrm{Li}^{1}$, Richard Sharpley ${ }^{2 *}$ and Sean Gammon ${ }^{2}$
}

*Corresponding author

rajsharpley@uclan.ac.uk

${ }^{1}$ School of Tourism Management, Sun Yat-sen University, Guangzhou, China (Postcode: 510275) email: limohan007@126.com

${ }^{2}$ School of Management, University of Central Lancashire, Preston. PR1 2HE.

Email: rajsharpley@uclan.ac.uk sjgammon@uclan.ac.uk

\begin{abstract}
The relationship between tourism and photography has long been subject to academic scrutiny. However, the extent research has adopted a primarily Western perspective, exploring the photographic practices of Western tourists. Conversely, more limited academic attention has been paid to the photographic practices of non-Western tourists. In particular, although China is now the largest source of international tourists, few attempts have been made to date to how and why Chinese tourists engage in photography during their international travels. This paper begins to address this gap in the literature, seeking to identify the extent to which the photographic practices of Chinese tourists are determined by what may be referred to as a 'Chinese tourist gaze'. Drawing on research undertaken amongst Chinese tourists in the UK, it reveals a number of influences that determine the nature and significance of the Chinese gaze, including the traditions of pre-modern travel in China, contemporary socio-economic transformations in China, the role of the Chinese state, and technology, the latter suggesting the increasing adoption of a more universal, de-exoticised (photographic) gaze.
\end{abstract}

Keywords: Tourist gaze; tourist photography; Chinese tourists; smartphone cameras; photoelicitation. 


\section{Chinese Tourist Photography: An Exploratory Study}

\section{Introduction}

An intimate relationship has long existed between the modern practices of tourism and photography. In other words, although people have for centuries engaged in various forms of tourism (or, more precisely, travel), Louis Daguerre's invention of photography in 1839 virtually coincided with Thomas Cook's first organised tour in 1841, an event that for many represented the beginning of modern mass tourism (Garlic, 2002). Since then, the histories of tourism and photography have been, as Teymur (1993: 6) suggests, so intertwined that it is difficult to separate them; indeed 'the emergence of mass tourism and popular photography owe a great deal to one another' (Belk \& Yeh, 2011: 345). Consequently, tourism and photography go hand in hand. 'To be a tourist... is to be, almost by necessity, a photographer' (Markwell, 1997: 131) or, as Haldrup and Larsen (2003: 24) alternatively observe, 'taking photographs is an emblematic tourist practice; it is almost unthinkable to travel for pleasure without bringing the light-weight camera along and returning home without snapshot memories'.

It is not surprising, therefore, that academic attention has long been paid to the phenomenon of tourist photography. Following the publication of Susan Sontag's (1977) seminal text On Photography, the practice of tourist photography - that is, why and how tourists take photographs, their relationship with the subjects of their photographs, and the significance of photography to the overall tourist experience - has been considered from a variety of disciplinary perspectives, as have the cultural and technological processes, particularly the advent of mobile technology and the camera phone (Larsen, 2008; Larsen \& Sandbye, 2014), that have rendered tourist photography an increasingly dynamic and complex phenomenon. Nevertheless, according to Stylianou-Lambert (2012), two contrasting perspectives dominate the literature.

On the one hand, and taking the lead from Sontag's (1977) argument that tourists exploit the opportunity to appropriate the places and people they visit through their photographs in a voyeuristic yet detached manner, it is suggested by some that tourists typically adopt a passive role when practising photography, seeking out and reproducing images previously encountered in postcards, guidebooks, tourism promotional materials and so on (Jenkins, 2003; Markwell, 1997). In so doing, they verify their anticipated experience, completing, as Albers and James (1988: 136) put it, 'a hermeneutic circle, which begins with the 
photographic appearances that advertise and anticipate a trip... and ends up with travelers certifying and sealing the very same images in their own photographic productions'. More specifically, it has been found that even tourists engaging culturally with the destination take photographs that reveal 'ideologies of Western power and dominance' (Caton \& Santos, 2008: 7) although other studies suggest more ambivalent evidence of a photographic hermeneutic circle (Garrod, 2008).

On the other hand, building upon Edensor's (2000) notion of tourists as performers, tourist photography has more recently been considered an embodied and proactive activity, as indeed has the consumption of tourism more generally (Bærenholdt, Haldrup, Larsen \& Urry, 2004; Larsen, 2005). That is, rather than being a passive form of consumption manifested in the capture of predetermined, representational images of places and people, it is suggested that, for tourists, photography is increasingly becoming a performance that 'lights up the tourist experience' (Scarles, 2009: 465). Tourist photography is now 'less concerned with spectatorship and "consuming places" than with producing place myths, social roles, and social relationships (Larsen, 2005: 417, emphasis in original). Moreover, this transformation to a great extent reflects the digital revolution in photography, with smart phone camera technology challenging not only the traditional sociology of photography in general (Bordieu, 1996; Gye, 2007; Harrison, 2004) but the role and significance of photography in the tourist experience in particular (Larsen \& Sandbye, 2014; Lo et al., 2011).

Irrespective of these debates, however, two points deserve emphasis. First, despite the increasing academic attention paid to the phenomenon of tourist photography, extant research continues to adopt a primarily Western perspective. In other words, the majority of studies are concerned with the photographic practices of Western (principally international) tourists; conversely, more limited attention has been paid to those of non-Western tourists. In particular, although China is now the world's largest source of international tourists, and research has begun to identify the factors that determine the behaviours of Chinese tourists in general (for example, Arlt, 2006; Nyiri, 2009; Pearce, Wu \& Osmond, 2013), few if any attempts have been made to date to explore how and why they engage in photography in particular during their international travels. This is not to say that photography as both an historical and contemporary cultural phenomenon in China has not benefitted from academic scrutiny (Roberts, 2013). For example, it is understood that, unlike in the West, early photography in China followed a tradition of expression rather than imitation (Moore, 2007); that is, 'even though photography was invented against a background of scientific fever and an urge to capture an absolute reality in Europe, this modernist ambition was mostly lost 
when it was introduced to China' (Wu \& Guoqiang, 2007: 32). Partly as a consequence (and partly reflecting the political-economy of China in the late nineteenth and early twentieth centuries) the widespread popular adoption of photography occurred later in China than elsewhere, explaining perhaps the historical and continuing popularity of studio portraits (Hay, 2007; Huang, 2006). However, few if any attempts have been made to consider the photographic practices of contemporary Chinese outbound tourists.

And second, many of these studies reflect or are influenced by the concept of the 'tourist gaze' (Urry, 1990; Urry \& Larsen, 2011). As noted above, it is now recognised that tourists both possess and express the ability to decide freely where to travel, what to visit and what to photograph and, indeed, to rewrite the prescribed meanings of tourist places through their photography. Nevertheless, their photographic practices tend to be culturally tailored or directed. That is, Western tourist photography is considered not to be 'natural' but subject to the influence both of tourism institutions and of cultural and technological forces which define it as the socially organised, reflexive and embodied practice of visually consuming what is extraordinary, prevalent and significant in contemporary society (Urry \& Larsen, 2011).

The purpose of this paper is to address these two issues. Specifically, drawing on research amongst Chinese tourists in the UK, not only does it analyse their photographic practices in general but also, in particular, it seeks to explore the extent to which the significance and nature of these practices are shaped by an identifiable set of cultural influences or, in other words, by what might be referred to as a Chinese tourist gaze. First, therefore, it is necessary to consider the potential constituents of such a gaze - that is, the cultural and other forces that might influence Chinese tourist photography - as a conceptual framework for the subsequent discussion of the empirical research.

\section{Conceptualising the Chinese tourist gaze}

As discussed above, contemporary research into tourist photography follows two distinct perspectives: as an activity that is either passive and manifested in the reproduction of prescribed images, or proactive, embodied and individualistic. Interestingly, the concept of the (Western) tourist gaze, first proposed by Urry (1990) and subsequently refined over two decades (Urry, 2002: Urry \& Larsen, 2011), embraces both. Fundamental to the concept is the socially constructed nature of the gaze. That is, what and how tourists gaze upon is largely influenced by a variety of social and cultural factors which, in a Foucauldian sense, both drive and inform the direction and focus of the gaze (Hollinshead, 1999). The gaze is, 
therefore, not fixed but dynamic, responding to wider socio-cultural transformations. At the same time, however, the tourist gaze is both reflexive and embodied: 'Places are chosen to be gazed upon because there is anticipation, especially through daydreaming and fantasy, of intense pleasures, either on a different scale or involving different senses from those customarily encountered' (Urry \& Larsen, 2011: 4). In other words, tourists visit places with which they engage physically and reflexively, interpreting, comparing and evaluating what they gaze upon (Urry \& Larsen, 2011: 17). Moreover, and of specific relevance to this paper, the tourist gaze has been fashioned by transport, information, communication and, in particular, photographic technologies; the gaze and photography have become enmeshed and transformed through advances in photographic and digital technology, endowing the tourist gaze / photography with dematerialised immediacy (Murray, 2008) and embodied performativity and, perhaps, contributing to the 'de-exoticisation' of the gaze, or a blurring of the tourist and everyday photography (Gye, 2007; Haldrup \& Larsen, 2010).

It is not the purpose here to consider the concept of the (Western) tourist gaze in detail (see, for example, Hollinshead \& Kuon, 2013). The point is, however, that the (photographic) gaze of non-Western tourists, such as those from China, may be similarly conceptualised; that is, it is logical to suggest that the photographic practices of Chinese tourists are similarly patterned or influenced by a distinctive set of cultural influences whilst displaying the increasingly widespread performativity of contemporary digital / smartphone photography. It has been suggested, for example, that Chinese international tourists typically prefer to gaze on what is distinctive or different, not simply to experience the 'Other' but to cast a comparative 'second gaze' (MacCannell, 2001) back on China as a form of patriotic identity reinforcement (Chan, 2006). More pragmatically, other commentators note that Chinese tourists take photographs to meet traditional family obligations; they capture images of places that they believe absent family members would like to see (Nyiri, 2006, 2009; Yeh, 2009). The question that remains, however, is what are the factors that may potentially define a distinctive Chinese tourist gaze?

A useful starting point in addressing this question is Pearce et al.'s (2013) review of the burgeoning literature into Chinese tourist behaviours. Not surprisingly, as China has emerged as the world's largest international tourist market - more than 127 million Chinese tourists travelled internationally in 2015 (UNWTO, 2016) - increasing academic attention has been paid to the scale, scope and nature of Chinese tourism, both domestic and outbound. Pearce et al. (2013) identify key themes in the literature, such as motivations, social behaviours and activities and interests, before offering a number of underpinning 'broad explanatory forces' 
(Pearce et al., 2013: 151) which they refer to collectively as a 'Triple-C Gaze'. This comprises Confucianism (to refer to the significance of harmony within traditional Chinese culture); Communism (broadly referring to the role of the contemporary Chinese state); and Capitalism (to refer to the increasing orientation towards consumerism in China).

Whilst highlighting undoubted influences on Chinese tourism, however, the alliterative 'Triple-C' concept is more descriptive than explanatory; that is, it describes three general characteristics of contemporary China yet - perhaps inevitably given its broad perspective is unable to reveal, for example, why particular sites / sights are gazed upon (and photographed) or how they are understood or interpreted. Nevertheless, it provides a valid framework for proposing more specific influences on the Chinese tourist gaze, as follows:

\section{The pre-modern travel gaze in China}

According to Pearce et al. (2013), traditional Chinese culture or, more precisely, Confucianism and its fundamental focus on harmony, continues to be a significant influence on contemporary Chinese tourism (see also Kwek \& Lee, 2010). However, the cultural dynamics of the Chinese tourist gaze, or the ways in which Chinese tourists see (and, specifically, take photographs), may in particular be better understood when related to traditional Chinese travel practices and their underpinning philosophies. A detailed consideration of the cultural history of travel in China is beyond the scope of this paper (see Gong, 2001) but, for the present purposes, two points deserve emphasis. First, early travellers in China from the pre-Qin Dynasty era onwards were often motivated by the search for tao, a concept that emerged from Yijing, the cosmological foundation of Chinese philosophy (J. Liu, 2006). Yijing established the principle that human beings exist in a network comprising other human beings (society), nature (heaven and earth), and the world as a whole, as well as in both the past and the future (Cheng, 1989). As a consequence of this inseparability, people can only learn about themselves and their world through their interactions with it but, at the same time, must learn to act within the bounds of their knowledge of the world. This interdependency between humanity and nature and knowledge and action explains the significance of 'harmony' to Chinese philosophies, whilst the search for tao, (tao being the source of all things), becomes a search for the 'truth' as a basis for learning, reflection and self-improvement. Significantly, therefore, prevailing philosophies encouraged pre-modern Chinese travellers not to gaze on nature in the detached, implicitly dominant manner that later came to define nineteenth century western sightseeing (Adler, 1989) but, rather, to regard themselves as part of nature. Hence, they tended to engage introspectively with what they 
were gazing upon to generate potential connotative meanings from it to guide their life and cultivate their character (Fung, 1922), an approach that, arguably, has been inherited by modern generations.

Second, travel in ancient China was considered to be a privileged activity undertaken by gods and immortals who would gaze down from elevated positions, such as mountain tops, on the panoramas beneath them. Moreover, legends from the Zhou Dynasty (c.1045 BC 256 BC) told of mountain-top encounters between travellers and gods / immortals, encounters which endowed the traveller with immortality. Hence, not only did some mountains come to be seen as sacred places, such as Taishan, or Mount Tai, which remains an important cultural site and tourist attraction in China, but also pre-modern travellers sought out these mountains and began to favour sublime views and panoramas, seeking the experience (and immortality) enjoyed by the gods (Brook, 1998; Gong, 2001). In so doing, they adopted a new way of seeing, a kind of mental travelling and contemplative gazing down from above over extensive panoramas, a visual practice referred to as guan (Chang, 2014: 40; Sullivan, 1979). Engaging in guan, travellers tended to deny their real self, imaginatively creating a picture of fantasy and / or interaction with what was being gazed upon. Consequently, their gazes were transcendent, reciprocal and expressive, characteristics which, again, potentially influence the contemporary Chinese tourist gaze. Indeed, research has revealed that contemporary Chinese tourists may create an imagined mental picture of the places they visit, perhaps reflecting an emphasis on 'decoration, worship [and] aesthetic expression' (Wu \& Guoqiang, 2007: 32) in early Chinese photography. For example, Chinese backpackers in Tibet often imagine a mysterious, magical and spiritual place; in effect, they tour an imagined rather than a real destination (Shepherd, 2009)

\section{The role of the Chinese state}

As noted above, the Western tourist gaze is, to a great extent, culturally determined, influenced by developments in technology and shaped by tourism institutions. In other words, the gaze is, in a sense, 'unregulated'; it responds to transformations in culture, increasingly globalized flows of information, advances in transport and other technologies and the activities of an innovative travel and tourism industry, whilst the role of the state is to facilitate such processes (Urry, 2000). In contrast, the Chinese state arguably remains a dominant force in determining the nature and direction of the Chinese tourist gaze. That is, despite significant political and economic transformations that have witnessed the decentralisation of authority and a shift towards a market economy, including within the 
tourism sector (Ryan \& Huang, 2013), the state retains its role in sustaining pre-existing ideologies and constraining social mobilities, especially the movement of ideas, images and sounds, through education, tourism and media (see Nyiri, 2006, 2009; Oakes, 1998). More specifically, tourism (and tourists) in China continue to be exploited by the state to support economic growth, promote cultural hegemony, to create an alternative or 'false' (Oakes, 1998) modernity and to reinforce national identity.

And it does so in two ways. First, through the development of tourist sites and attractions, the state seeks to develop an imagined nostalgic landscape (explicitly linked to pre-modern travel as discussed in the preceding section) as a foundation for building national identity and an alternative modernity (Anagnost, 1993; Kolås, 2004; Oakes, 1998). Specifically, the state promotes the construction of new scenic places and attractions and the rebuilding of existing heritage, typically as theme parks and open air museums (Nyiri, 2006, 2009), which are framed within pre-determined narratives and selectively rewritten cultural and historical meanings (Shepherd, 2009; 2014). Such narratives are reinforced through the media whilst state-run tourism bureaus indirectly control travel flows to these destinations. Hence, the gaze of Chinese tourists within China is directed by the state towards the pre-scripted national narratives of tourist sites, inevitably influencing how they then gaze on places during international travel.

Second, that gaze of outbound Chinese tourists is also influenced intentionally by the state, primarily through the manner in which the Chinese diaspora in Western countries are portrayed in the media in China (Arlt, 2006), specifically in Chinese-produced films and TV shows. Not only is international mobility encouraged and considered to be a sign of modernity China (X. Liu,1997), but major western cities are portrayed (in the Chinese media) as sites of an emergent global Chinese modernity (Sun, 2002). More specifically, the Chinese diaspora are shown to be contributing not only to their own individual modernisation but also, through their sense of connection to their cultural homeland, to the modernisation of China too (Nyiri, 2005). Hence, it has been noted that many international Chinese tourists seek to gaze on signs of modernity during their travels (Ong \& du Cros, 2012).

\section{Technology}

Although traditional film-based photography remained dominant for more than a century, over the last two decades it has become almost non-existent as digital photography has become increasingly widespread (Urry \& Larsen, 2011: 181). More specifically, the adoption of smartphones as means of taking, instantaneously viewing, sharing and deleting images has 
fundamentally transformed the practice and meaning of photography (Van House, 2011), not least through the popularity of the 'selfie' (Holiday et al., 2016). Not only has photography in general, as already observed, been de-exoticised as the 'everyday' is captured and shared (Gye, 2007), but tourist photography in particular has been simplified and transformed into a more controlled, performative, reflexive, de-materialised and social activity that has arguably become an increasingly fundamental element of the tourist experience (Haldrup \& Larsen, 2010). Moreover, not only is it estimated that in China in particular the number of smartphone users will have exceeded 600 million by 2017 (Statista, 2017), but also smartphone-based photo-taking and sharing is becoming ubiquitous (Zhang, 2017). Specifically, de Seta and Proksell (2015: 3) observe that 'selfies have entered Chinese popular culture along with camera phones...they imply a repertoire of poses, aesthetics and social rituals'. Therefore, it is logical to suggest that technological developments, particularly in digital and smartphone photography, are a fundamental influence on the Chinese tourist (photographic) gaze.

Overall, then, the Chinese gaze may be conceptualised as comprising three fundamental elements: pre-modern travel practices in China and their underlying philosophies; the influence of the Chinese state in directing the nature of the gaze; and technology, specifically the digitalisation of photography. Collectively, these suggest that Chinese tourists' photographic practices may be defined by the consumption of prescribed meanings of sites gazed upon but also the desire or opportunity to transcend, re-write or play with these meanings. The extent to which this is the case, to which Chinese tourists' photographic practices point to a distinctive 'gaze', is the focus of the research that is now discussed.

\section{The Research: Chinese tourist photography in the UK}

Given the purpose of the research, that is, to explore critically the photographic practices of Chinese tourists in the UK as basis for determining the influences on their photographic gaze, a qualitative approach utilising photo-elicitation, or what has been alternatively referred to as photo-interviewing (Hurworth, 2004), was adopted. Photo elicitation is, simply, the 'insertion of photographs in research interviews' (Harper, 2002: 13), and is employed because images may stimulate different or deeper responses than words alone. Widely used in tourism research (Cederholm, 2012), it can be, on the one hand, researcher-led and, on the other hand, respondent-led. In the former, photographs are pre-selected (and perhaps taken) by the researcher; in the latter, the photographs have been taken and a number selected by 
respondents prior to the interview, typically having received instructions from the researcher. The respondent approach is favoured by many, and was considered most appropriate for this research. Talking about photographs they have taken and selected encourages respondents to be comfortable and reflexive. More specifically, being allowed to select which photographs and what content to talk about, the respondent is empowered and a basis of trust and confidence is established (Oliffe \& Bottorff, 2007). Moreover, while selecting and discussing the photographs, not only is the respondent encouraged to reflect actively upon their photographic practices, emotional feelings and related subjective meanings, but also to review their everyday situation and past experiences (Cederholm, 2012)

The data for this research were collected from two consecutive studies. Initially, the researcher (the first author) joined a seven-day package tour around the UK organised by a UK-based Chinese tour operator. Two months prior to departure, the operator distributed research invitation letters to its potential adult (aged 18 and above) customers who intended to join the tour. Eventually, eighteen Chinese tourists on this tour participated in the research (see Table 1 for details).

Table 1: Respondent details: Study 1

\begin{tabular}{|l|l|l|l|l|}
\hline $\begin{array}{l}\text { Respondent } \\
\text { No. }\end{array}$ & Age & Gender & Profession & $\begin{array}{l}\text { Place of } \\
\text { Residence }\end{array}$ \\
\hline 1 & 26 & Male & Student & Shenzhen \\
\hline 2 & 45 & Female & $\begin{array}{l}\text { Primary school } \\
\text { teacher }\end{array}$ & Shanghai \\
\hline 3 & 25 & Male & Student & Suzhou \\
\hline 4 & 47 & Male & $\begin{array}{l}\text { Government } \\
\text { employee }\end{array}$ & Beijing \\
\hline 5 & 69 & Male & Professor & Guangzhou \\
\hline 6 & 58 & Female & Retired & Guangzhou \\
\hline 7 & 27 & Female & Self-employed & Shanghai \\
\hline 8 & 41 & Male & $\begin{array}{l}\text { Government } \\
\text { employee }\end{array}$ & Shijiazhuang \\
\hline 9 & 57 & Female & Retired & Zhengzhou \\
\hline 10 & 32 & Male & Graphic designer & Fuzhou \\
\hline 11 & 48 & Female & Self-employed & Jiamusi \\
\hline 12 & 26 & Female & Professional trainee & Chengdu \\
\hline 13 & 50 & Male & Self-employed & Quanzhou \\
\hline 14 & 21 & Male & Student & Beijing \\
\hline 15 & 45 & Female & Accountant & Guangzhou \\
\hline 16 & 25 & Female & Marketing assistant & Guangzhou \\
\hline 17 & 50 & Female & Engineer & Yantai \\
\hline 18 & 52 & Male & Engineer & Yantai \\
\hline
\end{tabular}


On each evening of the tour, pre-arranged interviews were conducted with two or three respondents who, having selected between three and five photographs they had taken that day, discussed them with the researcher, the conversations being digitally recorded and subsequently transcribed. All respondents were comfortable in discussing their feelings and stories behind their photographs; indeed, many developed a confident 'photovoice' (Warren, 2005), repositioning themselves in the places and moments when the photographs were taken.

However, it rapidly became evident that the younger tourists, those up to their early thirties in age, felt constrained by the rigid, controlled nature of the tour and its tight schedule, stating that (in comparison to the older generations on the tour) they preferred to have more time to roam freely and independently at each destination. With the implication that the younger Chinese tourists might adopt different photo-taking behaviours in less formal circumstances, a second study was undertaken by the researcher with a small group of Chinese tourists aged up to thirty years old whom he accompanied on a week's holiday on the Isle of Wight in southern England. Specifically, the group comprised six Chinese students, four female and two male, aged between 22 and 29 and all studying at a university in the UK. The trip involved visits to recognised natural and built / cultural attractions interspersed with periods of unstructured activities, such as relaxing on the beach. Similar to the first study, interviews were conducted with each respondent during which a number of their photographs and their experiences more generally were discussed. Again, all interviews were recorded and subsequently transcribed. The data from both studies were then coded and analysed thematically.

\section{Research outcomes: factors influencing the Chinese photographic gaze}

By way of introduction to a discussion of the research outcomes, it should be emphasised that the nature of the respondents' behaviour, both generally and with regards to their photographic practices, were context specific. In other words, in the first study the tourists' gaze was to a great extent structured by the planned and rigid tour in which they were participating; they had few opportunities to engage proactively and independently with the places they visited, gazed upon and photographed. Indeed, as noted above, whilst the older tourists displayed a traditional preference to travel as an organised group (Fu, Lehto \& Cai, 2012), the younger members of the tour group expressed frustration with its inherent 
inflexibility. In contrast, respondents in the second study not only delighted in the freedom that their self-organised trip afforded them but also, through their chosen behaviours, revealed a postmodern, playful approach to their tourist experience (Feifer, 1985). Specifically, they rejected more formal sightseeing (and photography) in favour of unstructured 'play'. As one respondent stated when comparing the attraction of Osborne House, built in the mid-1850s for Queen Victoria as a summer residence, to the nearby beach:

That is a very different thing. A Victorian house... You can learn a lot. You can think about the history. The house. But here, you see... I mean on the beach, you don't need to care about too much. You just try to be yourself. Don't care whatever you want to do. It is quite different

Moreover, as considered shortly, the subsequent discussion of photographs taken during the second study not only revealed significant cultural influences on the gaze of these younger tourists but also suggested, as others have also noted (Chow \& Murphy, 2008), increasing commonality between the gaze of Chinese tourists and that of their Western counterparts. Nevertheless, a number of themes emerged across both studies which, as now discussed, reveal the existence of what may be defined as a distinctive Chinese tourist gaze.

\section{i. The pervasive use of smartphone cameras}

The great majority of respondents relied on smartphones for taking photographs; indeed, even those respondents who also carried more complex digital cameras with them on the trip tended to favour their smartphones for capturing images. For many, the attraction of smartphones lay in their ease of use:

I am ... not good at using complicated cameras. After all, photo-taking to me is no more than a means of recording my travel experience. My photos are to be chiefly looked at by myself. I really don't like to edit the photos after a trip and show them off on the social media... A smart phone is enough.

However, the widespread use of smartphones by the respondents for capturing images of their trip also reflected a distinction between two Chinese words: 摄影 ('photography') and 拍 照 ('photo-taking'); the former is regarded as the preserve of professional photographers and artists, whilst the latter is associated with recording and subsequent sharing with 'distant others'. Many respondents alluded to the fact that they were not 'professional photographers', 
whilst one respondent in the second study observed:

Particularly as my parents have not travelled to the UK before, I wanted to take photos to show my parents when I am back to China - to tell them my travel experiences based around those photos.

Thus, the use of smartphones facilitated, for most respondents, two basic functions of their tourist photography: recording places they have been to and fulfilling traditional family obligations (Yeh, 2009). At the same time, a number of respondents implied that their

photography as tourists has become de-exoticised by the use of smartphones; that is, they took similar kinds of photographs whether at home or on holiday. One, for example, indicated she had a passion for flowers and using her smartphone enabled her to take pictures of flowers when and wherever she encountered them. Moreover, and as discussed shortly, for the younger tourists in the second study, the practice of smartphone photography (taking and sharing photographs, particularly of each other) became fundamental to their overall tourist experience. Indeed, the age of respondents was identified in the research as a significant influence on their photographic practices although, as will also be considered, their photographic gaze was not always age-dependent.

\section{ii. Influence of age}

The research revealed evident distinctions between the (photographic) gaze adopted by older respondents, or those around forty years of age and above, and that of younger respondents. For the older tourists, two specific characteristics of their gaze / photo-taking emerged from the photo-elicitation:

(a) Traditional, pre-modern gaze. As considered above, not only did early Chinese travellers regard themselves not separate from but part of nature, but they also gazed on nature introspectively. More specifically, although they engaged in the visual practice of guan (Chang, 2014: 40) - that is, imagining themselves as immortal in their gaze - natural spectacles such as a flowing river or leaves falling in autumn were, as recognised by Confucius and others (Ku, 1898), symbolic of the passing of time. Hence, early Chinese travelers were reminded of the inevitability of their own aging and mortality.

Interestingly, a similar response was identified amongst some of the older tourists in the first study. For example, one respondent (a 69-year old university professor) revealed that, on 
seeing (and photographing) a field of yellow rapeseed, he felt compelled to write in his dairy: 'These yellow blossoms have effective strategies to preserve their stunning beauty... they dare to face the indifferent and inhuman flowing of time with pride and dignity'. During an interview, he also lamented that:

You know, I am almost seventy. The time left to me is not too much, as I am getting older and older. I try my best to indulge myself in enjoying every single trip, as each one is an incredible opportunity for me... a younger person might not totally understand my feelings and my sense of sadness

At the same time, some older respondents implied that they would have welcomed the opportunity to immerse themselves more in nature, but were restricted by a tight schedule:

There is a saying in China: 'Appreciate the beauty of flowers on the side of road, while on the back of a galloping horse'. I think our appreciation of the views and tourist spots [on the tour] has been more brief and shallower than this.

I think it is much better if the tour guide could give me the opportunity to walk along the road to that valley over there...I really want to experience the wind, the soil and the smell in the air...

In other words, the respondents expressed the desire to gaze in a fashion similar to that adopted by their ancestors. Their experience was, however, often more superficial than they would have liked, their inherent wish to be part of what they were gazing upon and photographing being superseded by structure of the tour.

(b) Gazing on modernity / development. Previous studies have suggested that Chinese tourists are influenced to seek out and gaze upon signs of modernity during their international travels (Nyiri, 2005; Ong \& du Cros, 2012). This research similarly found that the older respondents in particular deliberately sought out and photographed representations of modernity or 'advancement', though not to simply celebrate or admire such modernity. Rather, it became evident that they deliberately gazed on aspects of modernity that highlighted what they considered to be problems or challenges in contemporary Chinese society. In other words, their gaze on modernity was, in effect, stimulated by not a patriotic but a critical 'second' gaze (MacCannell, 2001) back on China. For example, one female respondent, travelling with her daughter, took many photographs of and, during her interview, spoke at length about 
what she considered to be an effective interactive leaning opportunity for young visitors to the British Museum:

What actually impressed me was the collaboration and team spirit within a family. At the same time, it was fabulous to see the kids being encouraged to work out or build something instead of simply learning facts. This is very different from the situation in China, where kids just have the opportunity to view facts on a computer screen... Also, I saw how a teacher was delivering a history class to the kids. The teacher was dressed in the clothes from specific period in history, and sometimes acted as some political figure...The class was pretty dynamic... In contrast, the museums in our country are no more than stores for antiques. It is a shame. They fail to attract the kids back to the museum for another visit

She went on to say that she would upload her photographs onto social media to show her friends how how much 'better' she considered the learning experience to be in the UK. More generally, respondents frequently referred to the wide green spaces and traditional villages that they saw and photographed as they travelled past, comparing them favourably to the situation in China where they agreed that land is crowded, traditional built heritage has been destroyed and nature is presented in recreated theme parks, and where rapid economic growth and urbanisation has resulted in a variety of environmental and social problems:

If we compare these two countries, we can see that the English make good use of their land. The landscape is much better. Everywhere, especially the countryside, was beautiful, clean, organised and fantastic. Everywhere, what we see is a great picture.

In short, the gaze of the older Chinese tourists in this study was influenced significantly by what they considered to be negative outcomes of the state's social and economic policies, not least the attempt to direct the gaze of domestic tourists in China towards the prescribed meanings of reconstructed heritage and nature (Shepherd, 2009). Consequently, scenes of 'natural' countryside in the UK featured prominently in the respondents' photographs.

To some extent, the gaze and photographic practices of younger Chinese tourists, particularly those in the second study in this research, were similarly influenced by characteristics of contemporary China. Specifically, their gaze was revealed as a response to the dramatic social and economic transformations that have occurred in recent decades, though their gaze and activities differed from that of the older tourists described above. At the same time, however, they also displayed more 'traditional' behaviour, noted by others (Li, 2008), such as mentally immersing themselves in the landscape. Reference has already 
been made to the manner in which these younger tourists rejected 'formal' sightseeing at an historic property in favour of enjoying time on the nearby beach; nevertheless, their descriptions during interviews of this experience reveal that traditional element in their behavior. As one respondent explained:

... I became quite excited and wanted to play as soon as my feet touched the sea water... the movement of water gave me the feeling that I was interacting with nature. From my perspective, dead water is no more than being dead; while sea water is very different - it is living...I mean, because of the rise and fall of tide, I could feel the movement of sea water. It was strikingly different from dead, still and ordinary water

In a sense, this respondent became alive through her interactions with the sea. However, of greater significance was the explanation that she, and indeed other respondents, gave for wanting to 'play' on the beach; it represented for them an opportunity to escape temporarily from the realities of everyday life. Many of the respondents implied that not only had rapid socio-economic change in China resulted in a sense of alienation, but also they felt under pressure to succeed, to get a good job. Hence, gazing on and immersing themselves in the seascape combined the traditional Chinese way of gazing on nature with the more contemporary purpose of seeking emotional well-being through enjoying 'blue space' (Wheeler, White, Stahl-Timmins \& Depledge, 2012). For example:

It must be beach. When I saw the extensive and borderless sea, the pressures that I have been suffering recently almost disappeared. I was playing freely and cheerfully on the beach...You see this photo...

That's it! Compared to the vast and extensive sea, I was so tiny and trivial that nobody would care about what I was doing or would do. So I was crazily playing, running and taking photos on the beach... a lot of stuff, you see?

Moreover, for the younger tourists in the second study, taking photographs became central to the experience of the beach and other places they visited. That is, rather than capturing images of the scenery or other sights so that they could later mentally re-visit them or show them to others, they engaged in taking and subsequently sharing images of each other 'at play' (see, for example, Figure 1); taking and sharing their photographs became part of the experience of being there, part of the pleasure of the tourist experience (Haldrup \& Larsen, 2010). As one respondent remarked: 
Not only did such kinds of photo-sharing help to develop friendship and communication amongst us, but also it was an extra source of pleasure, particularly when we exchanged our thoughts about photographs with each other....Someone always joked about these photos ...

As such, the gaze of these younger tourists was subject to a number of influences, both traditional (being part of nature) and modern (contemporary life in China); however, their photographic practices were clearly defined by technology, the opportunities afforded by smartphones allowing them to take and share spontaneous, informal photographs. In this respect, therefore, their photographic gaze was not only de-exoticised but also conformed to the increasingly universal practice of embodied and personalised spontaneous photo-taking and sharing, reflecting the earlier observation that smartphone photography in general, and the taking and sharing of selfies in particular, has become as much an established social practice and cultural norm in China as elsewhere (de Seta \& Proksell, 2015; Zhang, 2017).

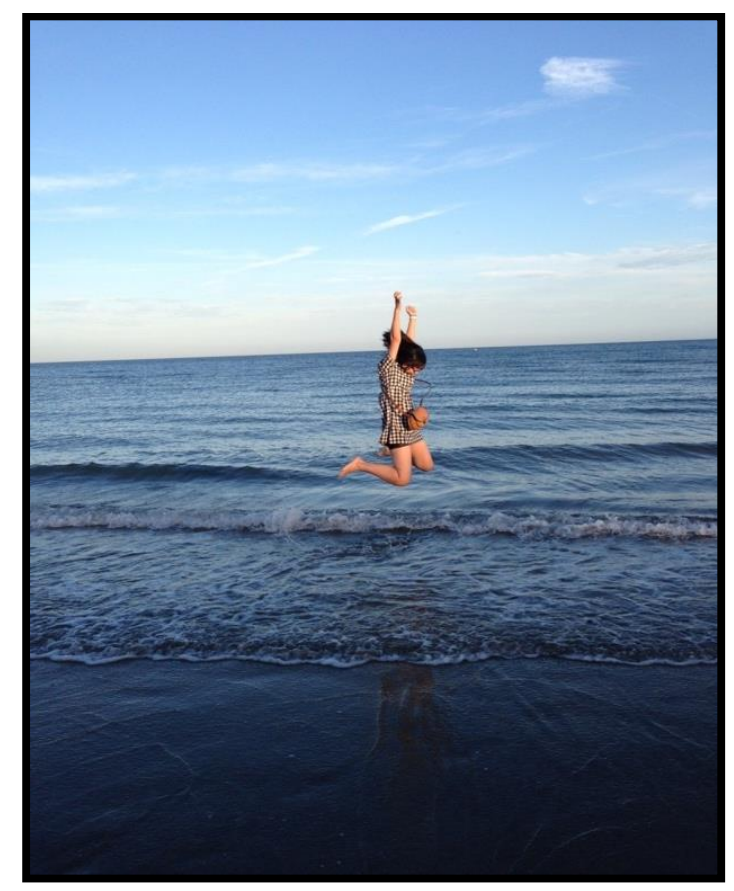

Figure 1: Playing on the beach (Respondent's photograph: reproduced with permission)

\section{iii. Stimulated desires - denying the self}

Irrespective of the age of respondents, the sense of alienation felt by the younger tourists in the second study and revealed in their photo-taking / sharing was also expressed by other respondents in the research, particularly those on the tour in the first study. However, rather 
than engaging in the playful activities and photographic practices demonstrated by the tourists in the second study, this sense of alienation was manifested in the significance and discussion of more 'traditional' photographs. More specifically, a number of respondents took photographs of natural, tranquil scenes and, in a manner similar to the transcendent gaze of pre-modern travellers in China, or the visual practice of guan, imagined themselves to be part of that scene. For example, in one interview, a female respondent from Shanghai spoke about her discomfort living in a crowded, fast-moving city and how, in a photograph she took of Loch Lomond in Scotland (see Figure 2), she imagined herself into the picture:

As for this photograph of Loch Lomond, I really like it because the lake offered [me] a sense of isolation and tranquillity. When I looked at it, I felt like I had become the boat on the lake...All the stress and bad feeling went away. I don't have to think about anything. Just to be there....a fantasy world...Yes, I like to be quiet, and living in a busy city sometimes makes me feel uncomfortable, shallow and superficial.

In other words, this respondent had the desire to consume something or somewhere that represented the counterpoint to her everyday life, something that would compensate for her discomfort and feelings of alienation. And to satisfy this need, she imagined herself as the boat in the tranquil scene of Loch Lomond, in so doing denying her 'self' and enjoying an extraordinary, tranquil though fleeting experience.

Others expressed similar feelings. For example:

Sometimes, when I have gazed upon a cloud hovering over an extensive wild area, I have felt very lonely and isolated, particularly when there was nobody else but me there. This feeling of isolation occasionally even brought me a hint of sadness. I think we, modern people, are becoming increasingly hollow and lonely...I live in a metropolitan city, which is full of change. Everything is changing so swiftly....

This respondent, however, imagined himself through his photographs to be living a more tranquil life in a provincial English city (Bath) that was on the tour itinerary; again, he denied his 'self' to become part of what he described or imagined as the 'happy world' of everyday life in that city. Hence, the everyday home life of these respondents directed them into a transcendent gaze; their photographs, therefore, were not simply records of what they had gazed upon, but desired images into which they could again place themselves. 


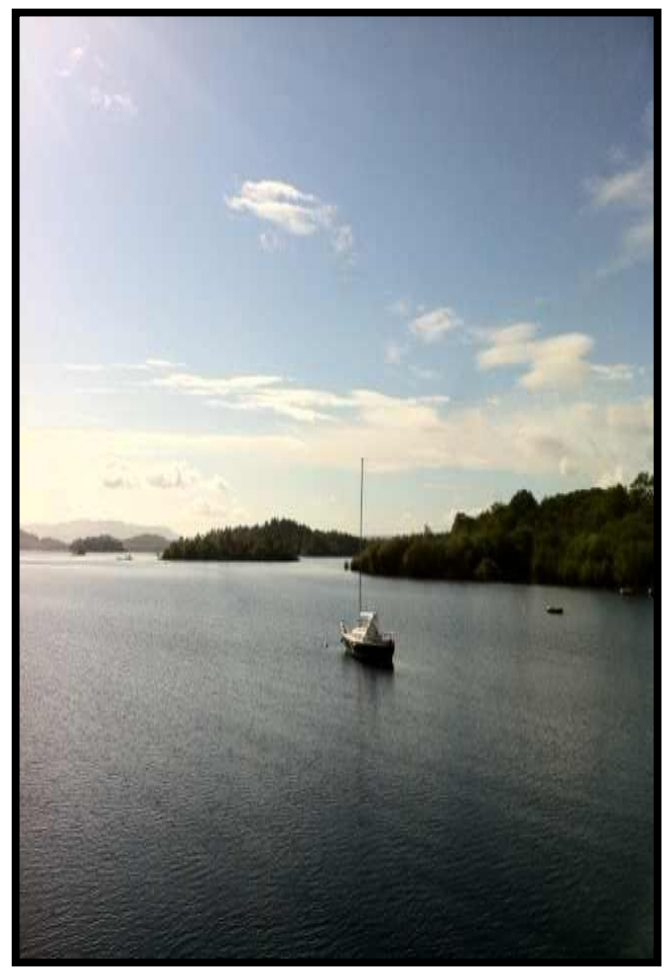

Figure 2: The boat on Loch Lomond (Respondent's photograph: reproduced with permission)

\section{iv. Imagined authenticity}

A final theme that emerged from the research was what is referred to here as the 'imagined authenticity' that was evident in the Chinese tourists' gaze and photography. Again as a manifestation of the traditional transcendent gaze of pre-modern Chinese travelers, in the interviews many respondents discussed how they mentally transformed places they gazed upon and photographed to fit a predetermined, imagined reality or authenticity. In other words, they were less concerned with seeing, understanding and capturing images of the reality of what they were gazing upon than with mentally transporting the scene into an imaged (perhaps idealised) authenticity.

For example, following a visit to Cambridge, one respondent (female, 45 years old) stated in an interview that: 'Cambridge made an incredible impression on me... The academic atmosphere at Cambridge University was very enriching and dynamic... a lot of photos of mine were taken there', adding that 'I saw the style of the buildings in the University was unique. Red bricks, aren't they? So I assumed that the students in this University studied very hard'. In other words, based solely on the style of the university buildings she had gazed upon (and extensively photographed) she imagined the authenticity of the university, in so 
doing thinking about her own student days: 'Since I hadn't studied hard while I was at University, I felt much regret while I explored...'

In a similar vein, another respondent, when discussing a photograph she had taken in Edinburgh, said:

You see, dark clouds covered the sky. It looked like demons would come to this world... to this place. Yes, I like Edinburgh very much, especially when dark clouds covered it. How to say? I like this sort of tranquillity before the storm. This view took me back to the 17th Century.

Despite all the evidence of modernity, such as shops and cars, and the presence of many other tourists, through gazing down a historic street in Edinburgh this respondent sensed an Edinburgh of the past, an Edinburgh facing uncertain times 'before the storm'. And this was an imagined authenticity that both excited and satisfied her, and she which attempted (albeit unsuccessfully) to recreate in a photograph:

If this bus disappeared, it [this photo] is really equivalent to a picture of Edinburgh in the 17th Century. This photo should have been much better. But this bus...

The extent to which this imagined authenticity was stimulated by the characteristics of the tour - that is, given the tight and rigid schedule, the tourists did not have time to immerse themselves in the reality of the destination - is unclear. However, even when they were given the opportunity to spend more time to wander freely, they tended not to do so. In other words, they displayed the 'typical' behavior of Chinese tourists (at least, those on organised tours) recognised by others, preferring to travel and remain in groups rather than exploring more independently (Fu et al, 2012). Hence, the imagined authenticity element of their gaze may be related to this cultural characteristic.

Overall, then, the research revealed a number of distinctive characteristics with regards to the gazed and photographic practices of the Chinese tourists participating in the studies. The question remains, however, as to what extent these characteristics are representative of a Chinese tourist (photographic) gaze.

\section{Conclusion: towards a Chinese tourist gaze?}

The purpose of this paper has been twofold; first, to address the lack of attention paid to the practices of non-Western, specifically Chinese, tourists in the tourism photography literature 
and second, in so doing, to consider the extent to which those practices reveal a distinctive set of influences that distinguish the Chinese tourist gaze from its Western counterpart. As discussed earlier in the paper, the (Western) tourist gaze is, according to Urry and Larsen (2011), the outcome of two broad sets of influences. On the one hand, it is socially and culturally fashioned; what and how tourists gaze upon (and photograph) is determined by their dynamic socio-cultural home environment which, it is controversially argued, encourages tourists to seek out and gaze upon the extraordinary or the 'exotic'. And on the other hand, it is becoming increasingly embodied and reflexive, not least through the opportunities afforded by digital technology and, in particular, the pervasive use of smartphones.

From the research discussed in this paper, it is evident that the gaze and, in particular, photographic practices, of Chinese tourists are similarly fashioned; that is, they share some of the characteristics of the (Western) gaze as originally conceptualised. Certainly, Chinese tourists experience, consume, make sense of and, though their photography, collect meaningful images of the people, places and cultures they gaze upon and, moreover, the manner in which they do so is shaped by a variety of social, cultural, institutional and technological forces. For the Chinese, tourism has become, as Urry (1990) observed in the case of Western tourism, democratised, and their gaze reflects transformations in social structures and tastes, the influence of social and political institutions and the dominant role of transport, information and communication technologies.

Nevertheless, the outcomes of the research suggest that the Chinese gaze differs in a number of ways (see Figure 3). First, it is evident that contemporary Chinese tourists have to some extent inherited the cultural gaze of pre-modern travellers in China. That is, in comparison to the values underpinning western 'sightseeing' (Adler, 1989) which, in effect, separate people from what they are gazing upon, Chinese tourists continue to not only place themselves in nature, in the world they are visiting, but also to engage in a variety of practices reminiscent of those of their forebears. For example, many respondents were found to favour a form of mental travel, engaging with the places and sights they encountered and photographed in a transcendental and inter-active manner, constructing and consuming an imagined authenticity. And more specifically, some of the older respondents visualised the passing of time in the scenes they encountered, further and distinctively rooting their gaze in the philosophical traditions of Chinese travel. At the same time, however, some recognised elements of contemporary Chinese culture were also evident in their gazes and photographic practices, not least recording images to fulfil family obligations. 


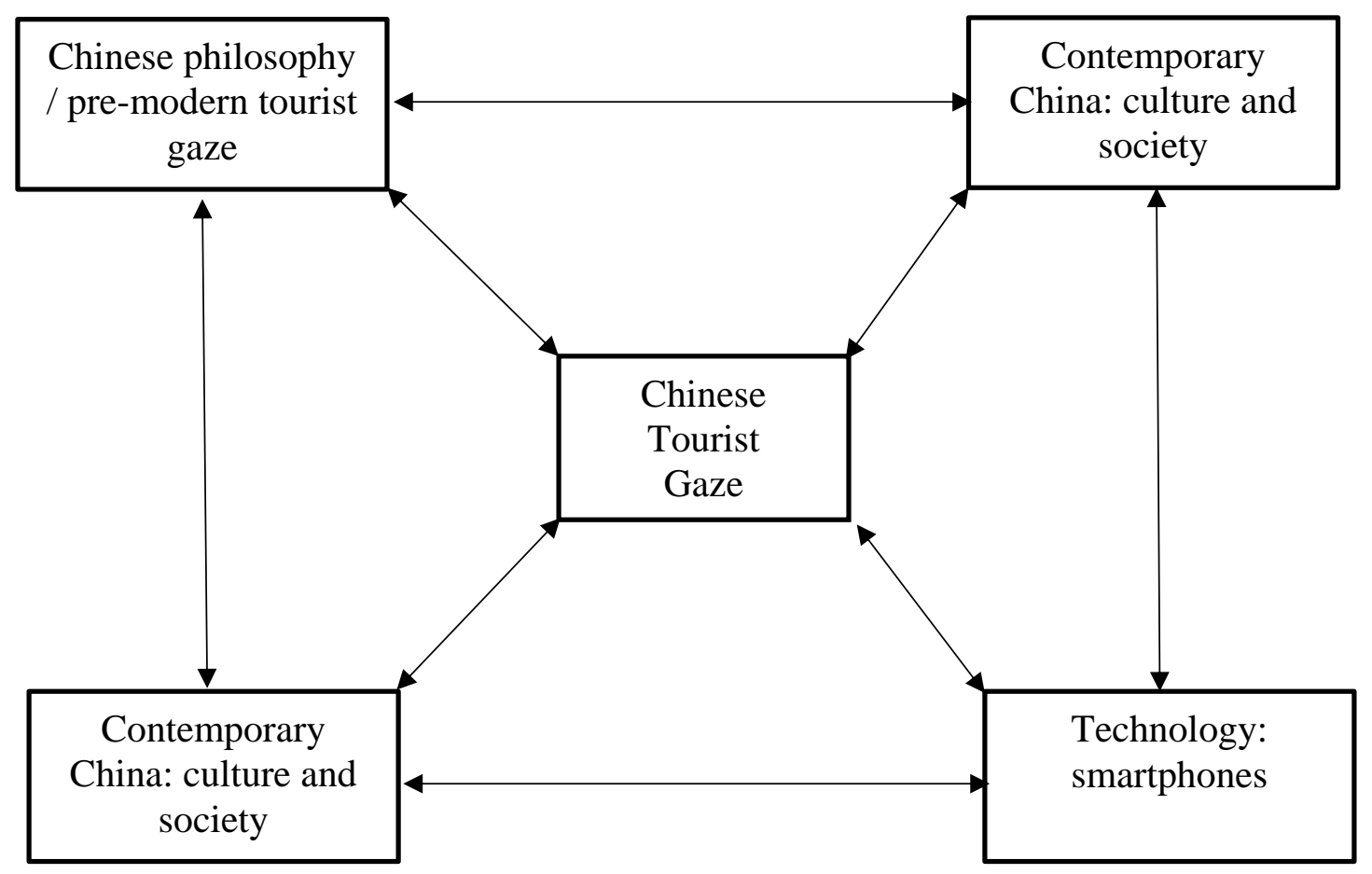

Figure 3: Influences on the Chinese tourist gaze

Second, it is apparent from the research that the gaze of many respondents was fashioned by recent rapid transformations in socio-economic conditions in China. For some, particularly the younger tourists but also some of the older respondents, a sense of alienation and expressed feelings of loneliness and shallowness encouraged them to gaze on and immerse themselves in places and sights that enabled them to escape temporarily from such feelings. In the second study, this was manifested most notably in the respondents' playful phototaking sharing - a practice that contrasts remarkably with more conventional concepts of the purpose and practice of tourist photography - whilst others compensated for the pressures of their contemporary life by engaging in the traditional practice of denying the self, imagining themselves into the scenes they gazed upon and photographed. More pragmatically, some respondents also delighted in gazing upon natural scenes untainted by pollution or environmental damage, or on aspects of life that considered more 'advanced' that that in China. In all cases, however, it could be argued that, unlike the alleged focus of the western gaze on the extraordinary or exotic, Chinese tourists seek to gaze on or experience the 
'ordinary' or 'normal' and, moreover, that their gaze is balanced by a negative 'second gaze' back towards China.

Third, and related, the role of the state remains dominant in shaping the Chinese tourist gaze. Not only have the economic policies of recent decades in China that have brought about rapid economic growth and urbanisation encourage Chinese tourists to adopt the gazes / photographic practices described above but, as discussed earlier in the paper, the Chinese state and its relevant institutions continue to employ tourism and the media as a means of achieving cultural hegemony, of normalising Chinese tourists' gaze and manipulating what they desire to see. However, in recognising the state-driven adaptation and commodification of natural and built heritage in China, Chinese tourist defy such attempts to achieve cultural hegemony; they gaze with pleasure on what they consider to be the natural, the traditional, the uncommodified places and sights encountered during their travels. In this sense, the Chinese gaze is a manifestation of resistance to the state.

To conclude, then, this paper suggests that, from the evidence of this research at least, there exists a distinctive Chinese tourist (photographic) gaze. That is, a number of influences upon can be identified that endow the gaze of Chinese tourists with a distinctive character. The extent to which this can be considered universal amongst all Chinese tourists will, of course be dependent on further research; not only there is a need to explore the (photographic) gaze of Chinese tourists in different contexts (and, indeed, of other nonWestern tourists), but also developments in the nature of Chinese outbound tourism, particularly the more widespread adoption of independent as opposed to organised travel, will enhance the dynamic nature of the gaze.

Nevertheless, two clear points emerge from the research. First, an evident relationship exists between an inherited traditional Chinese gaze and the gaze as a response to the contemporary socio-economic conditions in China. Indeed, the outcomes of this research reveal as much about the respondents' attitudes to socio-economic change in China as they do about the nature of their tourist gaze and photographic practices and, as such, they make a contribution to the related anthropology / photography literature (for example, Pinney, 2011). And second, the distinctions between the needs and activities of older and younger Chinese tourists, particularly the preference amongst younger tourists for playful, performative phototaking and sharing in which they themselves, rather than the places visited become the object of the photographic gaze, begin to challenge conventional perspectives on the practice and significance of tourist photography. 
Finally, although this paper has adopted a primarily conceptual perspective, these points in turn suggest a number of practical implications that arise from the research. For older tourists, the tour experience may be more satisfying if more time is allowed for them to gaze upon and immerse themselves in natural scenery and traditional built heritage rather than simply to 'collect' well-known sites; whilst capturing images to show to absent others remains an obligation, it is the culturally-influenced traditional gaze that adds meaning to Chinese tourists' photographic practices. The same may be said for younger tourists although their behaviours revealed by the research suggests that, over time, formal organised tours will be become less attractive to the Chinese tourist market. That is, independent travel will inevitably become more popular amongst Chinese tourists. Of greatest significance, however, the outcomes of this study imply that the continuing growth in outbound Chinese tourism may eventually contribute to demands for political change in China itself, although only time and further research will determine whether this will indeed the case.

\section{References}

Adler, J. (1989) Origins of sightseeing. Annals of Tourism Research, 16(1), 7-29.

Albers, P. and James, W. (1988) Travel photography: A methodological approach. Annals of Tourism Research, 15(1), 134-158.

Anagnost, A. (1993) The nationscape: movement in the field of vision. Positions, 1(3), 585606.

Arlt, W. (2006) China's Outbound Tourism. Abingdon: Routledge.

Bærenholdt, O. J., Haldrup, M., Larsen, J. and Urry, J. (2004) Performing Tourist Places. Aldershot: Ashgate.

Belk, R. and Yeh, J. (2011) Tourist photographs: signs of self. International Journal of Culture, Tourism and Hospitality Research, 5(4), 345-353.

Bourdieu, P. (1996) Photography: A Middle-Brow Art. Cambridge: Polity.

Brook, T. (1998) The Confusions of Pleasure: Commerce and Culture in Ming China. Berkeley: University of California Press. 
Caton, K. and Santos, C. (2008) Closing the hermeneutic circle? Photographic encounters with the other. Annals of Tourism Research, 35(1), 7-26.

Cederholm, E. (2012) Photo-elicitation and the construction of tourist experiences: photographs as mediators in interviews. In T. Rakić and D. Chambers (Eds), An Introduction to Visual Research Methods in Tourism. Bristol: Channel View Publications, pp. 92-107.

Chan, Y. (2006) Coming of age of the Chinese tourists: The emergence of non-Western tourism and host-guest interactions in Vietnam's border tourism. Tourist Studies, 6(3), 187-213.

Chang, M. (2014) Envisioning the spectacle of Emperor Qianlong's tours of southern China: An exercise in historical imagination. In J. Cook, J. Goldstein, M. Johnson and S. Schmalzer (Eds), Visualizing Modern China: Image, History and Memory 1750Present. London: Lexington Books, pp. 25-45.

Cheng, C-Y. (1989). Chinese metaphysics as non-metaphysics: Confucian and Daoist insights into the nature of reality. In R. Allison (Ed.) Understanding the Chinese Mind: The Philosophical Roots. Oxford: Oxford University Press., pp.167-208.

de Seta, G. and Proksell, M. (2015) The aesthetics of zipai: From Wechat selfies to selfrepresentation in contemporary Chinese art and photography. Networking Knowledge: Journal of the MeCCSA Postgraduate Network, 8(6), 1-27

Edensor, T. (2000) Staging tourism: Tourists as performers. Annals of Tourism Research, 27(2), 322-344.

Feifer, M. (1985) Going Places. London: Macmillan.

Fu, X., Lehto, X.Y. and Cai, L.A. (2012) Culture-based interpretation of vacation consumption. Journal of China Tourism Research, 8(3), 320-333.

Fung, Y.L. (1922) Why China has no science: An interpretation of the history and consequences of Chinese philosophy. The International Journal of Ethics, 32(3), 237263.

Garlic, S. (2002) Revealing the unseen: Tourism, art and photography. Cultural Studies, 16(2), 289-305.

Garrod, B. (2008) Understanding the relationship between tourism destination imagery and tourist photography. Journal of Travel Research, 47(3), 346-358.

Gong, P. C. (2001) The History of Travelling Spirit and Culture in China. Shijiangzhuang: Hebei Education Press. 
Gye, L. (2007) Picture this: The impact of mobile camera phones on personal photographic practices. Continuum: Journal of Media \& Cultural Studies, 21(2), 279-288.

Haldrup, M. and Larsen, J. (2003) The family gaze. Tourist Studies, 3(1), 23-45.

Haldrup, M. and Larsen, J. (2010) Tourism, Performance and The Everyday: Consuming the Orient. Abingdon: Routledge.

Harper, D. (2002) Talking about pictures: A case for photo elicitation. Visual studies, 17(1), $13-26$

Harrison, B. (2004) Snap happy: Toward a sociology of 'everyday' photography. In C. Pole (ed.) Seeing is Believing? Approaches to Visual Research, Studies in Qualitative Methodology Vol. 7. Oxford: Elsevier, pp. 23-39.

Hay, J. (2007) Notes on Chinese photography and advertising in late nineteenth-century Shanghai. In J. Kuo (ed.) Visual Culture in Shanghai, 1850s-1930s. Washington, D.C.: New Academia Publishing LLC, pp. 95-119.

Holiday, S., Lewis, M.J., Nielsen, R., Anderson, H.D. and Elinzano, M. (2016) The selfie study: Archetypes and motivations in modern self-photography. Visual Communication Quarterly, 23(3), 175-187.

Hollinshead, K. (1999) Surveillance of the worlds of tourism: Foucault and the eye-of-power. Tourism Management, 20(1), 7-23.

Hollinshead, K. and Kuon (2013) The scopic drive of tourism: Foucault and eye dialectic. In O. Moufakkir and Y. Reisinger (Eds), The Host Gaze in Global Tourism. Wallingford: CABI, pp. 1-18.

Huang, X. (2006) Performing gender: Nostalgic wedding photography in contemporary China. Ethnologies 282, 81-111.

Hurworth, R. (2004) Photo-interviewing. Qualitative Research Journal, 4(1), 73-79. Jenkins, O. (2003) Photography and travel brochures: The circle of representation. Tourism Geographies, 5(3), 305-328.

Kolås, Å. (2004) Tourism and the making of place in Shangri-La. Tourism Geographies, 6(3), 262-278.

Ku, H-M. (1898) The Discourses and Sayings of Confucius. Hong Kong: Kelly and Walsh Ltd.

Kwek, A. and Lee, Y.S. (2010) Chinese tourists and Confucianism. Asia Pacific Journal of Tourism Research, 15(2), 129-141.

Larsen, J. (2005) Families seen sightseeing: Performativity of tourist photography. Space and 
Culture, 8(4), 416-434.

Larsen, J. (2008) Practices and flows of digital photography: an ethnographic framework. Mobilities, 3(1), 141-60.

Larsen, J. and Sandbye, M. (2014) Digital Snaps: The New Face of Photography. London: I.B. Taurus.

Li, F-M. (2008) Culture as a major determinant in tourism development of China. Current Issues in Tourism, 11(6), 492-513.

Liu, J. (2006) An Introduction to Chinese Philosophy: from Ancient Philosophy to Chinese Buddhism. Oxford: Blackwell.

Liu, X. (1997) Space, mobility and flexibility: Chinese villagers and scholars negotiate power at home and abroad. In A. Ong and D. Nonini (Eds), Ungrounded Empires: The Cultural Politics of Modern Chinese Transnationalism. London: Routledge, pp. 91114.

Lo, I.S., McKercher, B., Lo, A., Cheung, C. and Law, R. (2011) Tourism and online photography. Tourism Management, 32(4), 725-731.

MacCannell, D. (2001) Tourist agency. Tourist Studies, 1(1), 23-37.

Markwell, K. (1997) Dimensions of photography in a nature-based tour. Annals of Tourism Research, 24(1), 131-155.

Moore, O. (2007) Photography in China: A global medium locally appropriated. IIAS Newsletter, 44, 6-7.

Murray, S. (2008) Digital images, photo-sharing, and our shifting notions of everyday aesthetics. Journal of Visual Culture, 7(2),147-163.

Nyiri, P. (2006) Scenic Spots: Chinese Tourism, Cultural Authority and the State. Seattle: University of Washington Press.

Nyiri, P. (2009) Between encouragement and control: Tourism, modernity and discipline in China. In T. Winter, P. Teo and T. Chang (Eds), Asia on Tour: Exploring the Rise of Asian Tourism. Abingdon: Routledge, pp. 153-170.

Oakes, T. (1998) Tourism and Modernity in China. London: Routledge.

Oliffe, J. and Botterff, J. (2007) Further than the eye can see? Photo elicitation and research with men. Qualitative Health Research, 17(6), 850-858.

Ong, C-E. and du Cros, H. (2012) The post-Mao gazes: Chinese backpackers in Macau. Annals of Tourism Research, 39(2), 735-754.

Pearce, P., Wu, M-Y. and Osmond, A. (2013) Puzzles in understanding Chinese tourist behaviour: Towards a triple-C gaze. Tourism Recreation Research, 38(2), 145-157. 
Pinney, C. (2011) Photography and Anthropology. London: Reaktion Books.

Roberts, C. (2013) Photography and China. London: Reaktion Books

Ryan, C. and Huang. S. (2013) Planning for tourism places. In C. Ryan and S. Huang (Eds), Tourism in China: Destinations, Planning and Experiences. Bristol: Channel View Publications, pp. 227-236.

Sontag, S. (1977) On Photography. New York: Delta Books.

Statista (2017) Number of smartphone users in china from 2013 to 2021. Available at: www.statista.com/statistics/467160/forecast-of-smartphone-users-in-china/ (Accessed 7 February 2017).

Stylianou-Lambert, T. (2012) Tourists with cameras: reproducing or producing? Annals of Tourism Research, 39(4), 1817-1838.

Sullivan, M. (1979) Symbols of Eternity: Art of Landscape Painting in China. Oxford: Oxford University Press.

Sun, W-N. (2002) Leaving China: Media, Migration and Transnational Imagination. New York: Rowman \& Littlefield Publishers

Teymur, N. (1993) Phototourism - or the epistemology of photography in tourism. Tourism in Focus, No. 6, pp. 6 and 16.

UNWTO (2016) Tourism Highlights 2016 Edition. Available at: www.eunwto.org/doi/pdf/10.18111/9789284418145 (Accessed 31 January 2017)

Urry, J. (1990) The Tourist Gaze: Leisure and Travel in Contemporary Societies. London: Sage.

Urry, J. (2000) Sociology Beyond Societies. Mobilities for the $21^{\text {st }}$ Century. London: Routledge.

Urry, J. (2002) The Tourist Gaze, $2^{\text {nd }} E d n$. London: Sage

Urry, J. and Larsen, J. (2011) The Tourist Gaze 3.0. London: Sage.

Van House, N. (2011) Personal photography, digital technologies and the uses of the visual. Visual Studies, 26(2), 125-134.

Warren, S. (2005) Photography and voice in critical qualitative management research. Accounting, Auditing \& Accountability Journal, 18(6), 861-882.

Wheeler, B., White, M., Stahl-Timmins, W. \& Depledge, M. (2012) Does living by the coast improve health and well-being? Health and Place, 85(5), 1198-1201.

Wu, J. and Guoqiang, Y. (2007) Beyond propaganda, aestheticism and commercialism: The coming of age of documentary photography in China. Javnost - The Public, 14(3), 3148. 
Yeh, J. (2009) Still vision and mobile youth: Tourist photos, travel narratives and Taiwanese modernity. In T.Winter, P. Teo and T. Chang (Eds). Asia on Tour: Exploring the Rise of Asian Tourism. Abingdon: Routledge, pp. 302-314.

Zhang, W. (2017) Smartphone photography in urban China. International Journal of Social, Behavioral, Educational, Economic, Business and Industrial Engineering, 11(1), 2312-239. 